\title{
Olowalu Review: Developing identity through translanguaging in a multilingual literary magazine
}

\section{Revista Olowalu: El desarrollo de la identidad a través del translingualismo en una revista literaria multilingüe}

Alex Josef Kasula ${ }^{1}$

Citation/ Para citar este artículo: Kasula, A. J. (2016). Olowalu Review: Developing identity through translanguaging in a multilingual literary magazine. Colomb. Appl. Linguist. J., 18(2), pp. 109-118.

Received: 27-Jan-2016 / Accepted: 08-Jun-2016

DOI: http://dx.doi.org/10.14483/calj.v18n2.10014

\begin{abstract}
With the current trends in our globalized society, there is a clear increase in multilingualism; however, the understanding of multilingual identity and policy towards education stays relatively the same. Recent investigation in multilingualism in the US has shed light on the positive impacts of alternating policy in language education with regard to a greater understanding of how translanguaging and identity impact the language learner and language learning policies (García \& Wei, 2013). The following article describes the development of an online multilingual literary magazine, Olowalu Review, that aimed to provide English language learners in an English-only language policy with a space to translanguage. Thus, having the opportunity to develop and express their multilingual identities. Goals and the development of the magazine are described in terms relating to current multilingual theory. While the outcomes and findings reveal how Olowalu Review enabled multilinguals to foster and exercise multilingual identities and skills, raise multilingual awareness, and act as an important multilingual artifact through an analysis of written submissions and interviews with authors. Pedagogical implications are discussed to empower language teachers, learners, or artists to develop the same or similar project for their own local, national, or global community.
\end{abstract}

Keywords: identity, L2 creative writing, L2 literature, multilingualism, translanguaging

\section{Resumen}

Con las tendencias actuales en nuestra sociedad globalizada, vemos un aumento en el multilinguismo; sin embargo, el entendimiento de la identidad y la política multilingüe hacia la educación se mantiene relativamente igual. Investigaciones recientes en multilingüismo en los EE.UU. ha arrojado luz sobre los impactos positivos de la alternancia política en el lenguaje educativo con respecto a un mayor entendimiento en cómo el translanguaging y la identidad impactan al estudiante de idiomas y las politicas de aprendizaje de idiomas (García y Wei, 2013). El siguiente artículo describe el desarrollo de una revista literaria multilingüe en línea, Olowalu Review, la cual tuvo como objetivo proporcionar a los estudiantes de inglés en un inglés único de política lingüística en un espacio para translanguage. De esta manera tener la oportunidad de desarrollar y expresar sus identidades multilingües. Las metas y el desarrollo de la revista se describieron en términos relativos a la teoría multilingüe actual. Si bien los resultados y hallazgos revelan cómo Olowalu Review se habilitó multilingüe para fomentar y ejercer las identidades y habilidades multilingües, aumentar el conocimiento multilingüe y actuar como un importante artefacto multilingüe a través de un análisis de las

1 Universidad de Los Andes. Bogotá, Colombia. aj.kasula@uniandes.edu.co 
comunicaciones escritas y entrevistas con los autores. Las implicaciones pedagógicas se discutieron para permitir a los profesores de idiomas, estudiantes o artistas desarrollar el mismo o un proyecto similar para su propia comunidad local, nacional o global.

Palabras clave: identidad, la escritura creativa L2, literatura L2, multilingüismo, translanguaging

\section{Introduction}

As the understanding of multilingualism in the growing globalized society and in the language learning classroom begins to expand, there is a clear need for teachers, students, and policy to understand how this effects the identities of learners and speakers of more than one language. The ideas of national languages are beginning to diminish, as the global flow of people and information is more rapid than ever, making a visible path for a stronger role of multilingualism in language learning classrooms. The work of García, Zakharia, and Otcu (2013) reveals how in falsely understood monolingual societies like New York City, U.S.A., being a multilingual is common and the need for education to be a reflection of the identities of those who are learning and teaching. Multilingualism expands beyond just that of super-diverse communities like seen in New York City, but also throughout the world as language requirements are becoming a core part of educational curriculum.

There is a clear demand for pedagogy and course design to meet the ever-changing identities of multilingual language learners. Therefore, a distinct understanding of what is 'multilingualism' is necessary for all stakeholders in language learning to comprehend in order to progress the ways of teaching and learning to sufficiently reach the rapidly changing language use of the learners. Cenoz (2013) describes the holistic view of multilingualism in which multilingual speakers use their linguistic resources in ways that are different from the way monolingual speakers use single languages. Although a number of more specific definitions have stemmed from a general understanding of multilingualism, the current definition adequately depicts multilingualism in the context of translanguaging and the pedagogical implications this article aims to provide the readers.
The following article will discuss how the development of an online multilingual literary magazine for English language learners can act as an effective outlet for multilinguals or emerging multilinguals to express their multiple identities, while also providing the opportunity for learners to exercise the language skills they are learning. To understand how to approach multilingualism in the English language learning (ELL) classroom, it is vital to grasp what is occurring with multilinguals in regards to their self-identity and how this can be expressed in class activities beyond what occurs directly in the classroom.

\section{Identity and Translanguaging}

A number of societies and populations around the world are multilingual; a clear example are the urban dwellings in the U.S. that hold a large diversity of multilingual speakers (see García, Zakharia, E Otcu, 2013 for a list of languages spoken other than English in New York City). Multilingualism expands beyond the U.S. as globalization demands citizens from all nations to acquire a second language, primarily languages of former imperialistic societies, such as English, French, Spanish, Mandarin Chinese, and so on. This does not account for societies across the world that practiced multilingualism prior to global colonialism and modern globalization (see Canagarajah \& Liyanage, 2012, for a more elaborate discussion). With an increase in multilingualism throughout the world, the questions of "how do these multilinguals communicate?"; "how do multilinguals manage the uses of their multiple languages?"; and "how do multilinguals use language to identify themselves?" begin to emerge. Translanguaging is a social concept that aims to discuss the use of language among multilinguals, and is a common phenomenon among multilinguals playing a fundamental role in terms of communication, identity, and power. Translanguaging is an approach to the use of language that considers the language 
practices of multilinguals not as using two or more autonomous language systems as has been traditionally the case, but as one linguistic repertoire with features that have been societally constructed as belonging to two separate languages (García $\varepsilon$ Wei, 2013). For a visible contextualization of translanguaging in literature see Excerpt 3.

Translanguaging is a common phenomenon for multilinguals, at points feeling the most natural form of communication or expression. Translanguaging acknowledges the multiple identities and languages of its speakers through creating a space where values, culture, language, and history can be expressed. In this space, one is languaging, which is the process to gain knowledge, make sense, or communicate by putting one's thought into actual form (Swain, 2006; Wei, 2010). Wei continues to describe how the translanguaging space "is not a space where different identities, values and practices simply co-exist, but combine together to generate new identities, values and practices" (p. 1223). Although this space is fluid and ever changing for those who inhabit it, it provides the opportunity for expression of multilinguals, as many multilingual environments are falsely perceived as monolingual. A clear example is in the U.S. education system. Although multilinguals make up a large portion of students attending public schools in the U.S., many are forced into speaking in English through the "English-only" policy, and in turn multilinguals are put at a disadvantage, inevitably forced into circumstances where their linguistic identities and translanguaging space are suppressed (García, Zakharia, \& Otcu, 2013). The use of "Englishonly" policies extends beyond languages where English remains understood as national language. English-only policies, or monolingual polices, can be found across language learning environments geographically and linguistically, with clear examples in Europe (Phillipson, 2003) and South America (De Mejía, 2005).

Nevertheless, when multilinguals and their identities are accepted, appreciated, and heard, these multilinguals become empowered, fostering the equity needed in democratic societies (see Davis, 2009, for an example of empowering multilingual youth). The ability to use the full linguistic repertoire through translanguaging and abolish the enslavement of multilinguals into one "standard" language space not only promotes equity and appreciation of cultural differences but can also be viewed as an innate right. Phillipson (1998) describes how multilingualism strongly connects with human rights by allowing speakers to express their linguistic diversity and counteract linguistic dominance. It is the responsibility of the stakeholders in language education to transform or provide space for translanguaging as it not only can be a useful resource for learning and communicating but also help foster identities of learners, promoting a more democratic and equal environment. Offering opportunities to translanguage gives voice to those who are marginalized, to those still wandering the borderlands of language.

\section{Translanguaging Theory to Practice}

Although translanguaging is a rather new term in the field of linguistics, it has long been a method of expression for those living within multilingual communities. The work of Gloria Anzaldúa, Borderlands/La Frontera: The New Mestiza (1987), describes the lives of multilinguals living on the "borderlands" of society through her poetry and short essays. She, a Latina bilingual in Spanish and English near the Mexico-U.S. border, translanguages to express the lives of people within her multilingual community. In Anzaldúa's work a strong focus is on the individuals in the borderlands and the perplexity with their identity and sentiment of living on the fringes of two societies, not being fully accepted into one, or the other. Providing the space for translanguaging of language learning students could not only erase the borders felt in Anzaldua's work but also be the place to foster new identities and opportunities to learn.

As mentioned above, there may be initial negative recoil from the misunderstood genuineness of translanguaging, specifically where monolingual policies are strict. García, Zakharia, and Otcu (2013) clearly displays how teachers can become facilitators of translanguaging spaces in the classroom, even if they are unfamiliar with the students' first language (L1) or second language (L2). García, Zakharia, and Otcu also illustrate the positive effects of 
a translanguaging space, where students and community feel more involved and exceed the standards of the class. By giving the opportunity to express language through translanguaging, leaners have the ability to draw on resources from any language in their linguistic repertoire and feel comfortable using these resources (García, Zakharia, E Otcu, 2013). Although there is not a sufficient claim that translanguaging will increase language "skill", it does open the door for practicing literary skills required of the target and native languages. Sayer (2013) found that in a multilingual elementary classroom the use of an adaptable bilingual pedagogy increased translanguaging in the classroom, helping students to make sense of content and learn language, while also legitimized methods of accomplishing desired identities.

However, most research has looked at ways educators have promoted translanguaging inside the classroom. Providing learners to express themselves outside of the classroom not only offers an opportunity for the learners to translanguage but deepen arts and expression within their own identity or possibly the community. Translanguaging outside of the classroom has occurred specifically within art forms transnationally and transculturally through the use of international hip-hop (Alim, Ibrahim, $\varepsilon$ Pennycook, 2009) and in creative writing literature (Anzaldúa, 1987). By providing creative outlets for learners to exercise their multilingualism, activities such as the development of a literary magazine could be a one of the simplest yet effective opportunities for learners to translanguage.

\section{Olowalu Review}

The following sections describe the development of an online literary magazine, Olowalu Review (Olowalu meaning "of many voices" in Hawai'ian), by an ELL instructor at a mid-sized university in Hawai'i. Olowalu Review was developed partially due to an "English-only" policy within the instructor's own institution of near one-hundred students, and the lack of opportunities for students to express their unique multilingual identities. The English-only policy was highly valued as there was a fear that students would self-segregate according to their L1s and not use the target language of the institution, English. Rather than disobey the longstanding policies of the department, the instructor chose to develop a platform outside of class, that was not only open to his students but also the entire university, local, and national communities. The lack of space for the linguistically diverse body of learners to use their L1, L2, or other languages acquired only served to increase the need for such a platform of self-expression through translanguaging. Learners, restricted within monolingual policies throughout the university and the country, had very few known opportunities to express and create new identities or generate space where their voices could be heard especially among some of the students' minority languages such as Arabic or Hawai'ian.

\section{Development and Submissions}

One of the core elements of any literary magazine is finding contributors and generating an audience to read it. Therefore, in order to find contributors interested in the writing for the magazine, language department heads at the university were contacted and asked to email or pass out a paper copy of a flyer for submissions. Of the thirty-two language departments at the instructor's institution, twentyeight responded and had handed out flyers or emailed submission details to the enrolled students. Submissions to Olowalu Review were also posted on several local Facebook pages for creative writing. Additionally, to gain wider contribution, diversity in language use, and to spread translanguaging awareness, three different contacts at three different U.S. mainland universities were contacted and posted submission flyers. Several forms of art and literature were accepted as a part of Olowalu Review, including but not limited to poetry, fiction, nonfiction, and visual art. The only requirement for submission was that the piece was either creative art or literature through the use of multilingualism.

The second coreelement during the development of Olowalu Review was finding a unique, open, and cost-effective platform to display the submissions. Therefore, the most efficient and accessible platform to develop Olowalu Review was through the use of a free online website designer. The platform selected was through that of Wix.com, although there are several resourceful and professional websites to 
choose from. However, before submissions and the development of Olowalu Review could take place, it was fundamental that the magazine had clear and distinct goals of what it was trying to accomplish in terms of translanguaging and multilingualism.

\section{Goals of Olowalu Review}

In order to make an impact, spread awareness, and create a realistic space for translanguaging to occur, Olowalu Review developed five definite goals based upon multilingual literature in the field of language learning. These goals were heavily influenced by the above literature on multilingualism, identity, and translanguaging. Below each goal is described in terms of setting a vision for Olowalu Review that is consistent with the call for developing translanguaging spaces for multilingual leaners and speakers as well as serving as an outlet for art and expression within the community and larger society. The goals are as follows:

1) Raise multilingual and translanguaging awareness. There is clear evidence that the world is becoming more multilingual and the amount of students and learners who translanguage is increasing, as this is a common phenomenon among multilinguals, regardless if they are confined within a falsely perceived monolingual environment of English-only policy (García, Zakharia, E Otcu, 2013). Through raising awareness of multilingualism and translanguaging, leaners and speakers are empowered, creating more cultural understanding and provide a path to understand the borderlands of language (Davis, 2009).

2) Promote multilingual use and identity. Multilinguals have stories, experiences, and history that not only one voice can tell, as seen in Anzaldúa's work (1987). It is clear that translanguaging happens on a global level, for example in transnational hip-hop (Alim, Ibrahim, \& Pennycook, 2009); however, there are limited known contexts where it is acceptable for multilinguals to translanguage. To reach the large amount of multilinguals there needs to be a variety of platforms for acceptance, expression, and construction of identity. Olowalu Review acts just as one of the several platforms that could be used to do this.
3) Enable speakers and writers to exercise their multilingual knowledge. Building off of the above goals, Olowalu Review is open to multilinguals of any proficiency, age, or linguistic background. One of its purposes is to be a space where multilinguals or emerging multilinguals can express themselves and use resources from their full linguistic repertoire to practice language or develop identity.

4) Contribute as another resource and example of translanguage/multilingual literature. With the lack of artifacts in translanguaging and multilingual literature, Olowalu Review can act as a foundation for future research projects or as activities for pedagogical practices in multilingualism.

5) Promote arts and expression in the local, national, and global communities. Language is art, and translanguaging is language. With the ability to have submission from all over the world through an online platform the art has the ability to express local and global perspectives, crossing borders and borderlands. The understanding and appreciation of literature and art plays a fundamental role in challenging current paradigms both individually internal, and on a societal level.

After goals had been established, call for submissions posted, and the website designed, there was a three month period in which the instructor that developed Olowalu Review communicated with authors and uploaded submissions to the magazine's website. Then after the three-month period, the magazine went live online and was openaccess to the authors and the public. Following the magazine going live, the outcomes and findings of the magazine were examined and feedback was gathered from the authors.

\section{Outcome}

For the first issue of the multilingual magazine, expectations of the instructor were met, but not exceeded. There were a total of twelve submissions by fourteen contributors that used thirteen different languages, claiming their "hometown" from eight different countries. Five of the submissions came from the instructor's English language institution, while eight came from the instructor's university. The 
remaining four submissions came from students at universities in the mainland U.S.A.; a total of seven poems, four non-fiction short stories, and one fictional short story were submitted. Table 1 shows the submission details of the authors.

Table 1: Olowalu Review Submissions

\begin{tabular}{ccccc}
\hline Piece & Authors & Type & Languages & Hometown \\
\hline Calle San Miguel & 1 & Poem & English, Russian, Spanish & Illinois, U.S.A. \\
E Lei & 1 & Poem & English, French, Hawaiian & Hawai'i, U.S.A \\
El Humo Francés & 1 & Poem & English, Spanish & Illinois, U.S.A. \\
地球生態的保護意識 & 3 & Nonfiction & Chinese, English, Spanish & Taiwan; U.S.A.; U.S.A. \\
Environmental Protection & 1 & Nonfiction & English, Korean & Seoul, Korea \\
First Day at Niagara Falls & 1 & Poem & English, Spanish & Guildford, England \\
La Máquina & 1 & Fiction & English, Spanish & Jalisco, Mexico \\
Life in the Mountains & 1 & Poem & English, German, Italian, Korean, Slavic & Seoul, Korea \\
넌어 사랑 & 1 & English, Thai & Bangkok, Thailand \\
On Professionalism & 1 & Nonfiction & English, Arabic & Najaf, Iraq \\
Sleep Softly & 1 & Poem & English, Japanese & Chiba, Japan \\
Time Goes By & 1 & Poem & English, German & Seoul, Korea \\
Was I want to tun in Hawaii? & 1 & Nonfiction & &
\end{tabular}

\section{Methodology}

This article primarily focuses on the praxis of translanguaging and its potential pedagogical implications; however, there was a methodology applied to the analysis of the submissions to gain a deeper understanding of such a project's utility for multilinguals to express themselves in a translanguaging space.

The approach taken by the instructor at the U.S. institution, who also was the developer of Olowalu Review and researcher, took a qualitative approach in interpreting the data but did not have any participatory involvement influencing the literary submissions of the authors. He stayed relatively inactive in the writing process of the authors as the goals of Olowalu Review, stated above, prefer Olowalu Review to be a free space of multilingual literary expression, allowing authors to use their linguistic repertoire freely, promoting multilingual use, awareness, and artistic expression. Rather, he took an editorial approach towards the submissions, simply responding to inquiries about one-time submission guidelines. The intention was to allow translanguaging to happen "naturally" and not solicited by another individual (Canagarajah, 2011). However, small-scale interviews were conducted both via email and in person to seek out perceptions and attitudes of the writing process from the authors. Data gathered through interviews did not aim to understand how the translanguaging occurred but rather how it complimented what the writers wanted to express in their literature.

Submissions were briefly analyzed by adapting Canagarajah's (2013) framework of analyzing translingual academic essays, identifying the literary pieces as viewing the submissions as results of code-meshing, which Canagarajah describes as a "form of writing in which multilinguals merge their diverse language resources with the dominant genre conventions to construct hybrid texts for voice" (p. 40). Through the lens of code-meshing, Canagarajah's four strategies were taken into consideration into how specifically the author's may have used translanguaging to express their unique literary voice, his four strategies being: envoicing, recontextualization, interactional, and entextualization. A brief explanation of each strategy according to its relevance to the current project is outlined below according to Canagarajah (2013, p. 50):

Envoicing is the use of translanguaging where writers mesh semiotic resources for their identities and interests to explain attitudes representing writers' voice. 
Recontextualization intends to structure the text according to the desired genre and communicative conventions.

Interactional strategies attempt to aid the reader and writer to co-construct meaning of the text through ecological resources and to achieve understanding despite language differences, and

Entexutalization where text construction helps aid in the author's voice and meaning, for instance, in Canagarajah (2013) this was through the use of numerous drafts, feedback, and revision of one text. However, this strategy does not apply to the current project, as the researcher did not aid authors in revision or feedback of their texts.

Canagarajah (2013) describes these four different strategies as methods of multilinguals expressing their literary voice as ways of meaning making through the writers' semantic resources in code-meshing. Although meaning making should always be taken into consideration, the current article analyzes and discusses these strategies as ways for the writers to express their multilingual voice within a completely open translanguaging space.

\section{Findings}

After the online publication of Olowalu Review, it was clear that all submissions did translanguage by using more than one language to express the idea, story, or emotion behind the author. Although not all submissions were thoroughly probed into how the translanguaging occurred, it is clear that the authors who submitted felt they could express their multilingual voice through creative literature and translanguaging. When briefly analyzing the submissions to Olowalu Review, its visible that each author translanguaged differently, and had different ways to express their linguistic background and identities. Also, it is clear that when given the space, people express themselves through language differently, with different stories, different languages, history and culture, thus finding the need to translanguage differently. Where some pieces used one language dominantly, others distribute language use quite evenly throughout their piece. Some author's chose to translanguage as a literary device, creating "linguistic imagery" to convey thoughts or stories by voicing certain elements of the piece to awaken the reader's auditory perceptions. This can be seen in Excerpt 1.

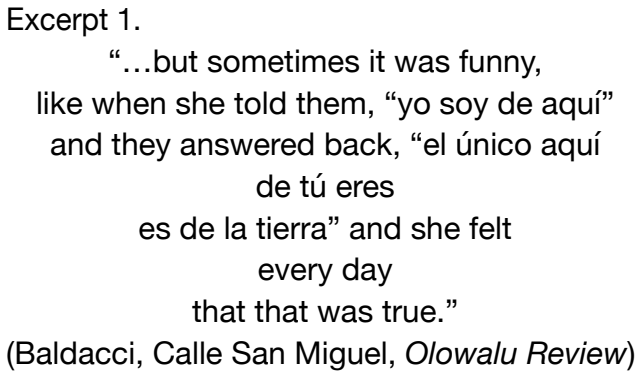

In Excerpt 1, the author conveys her thoughts by utilizing resources in her full linguistic repertoire to write about experiences, history, or thoughts that reflect her voice and identity. However, she does so by translanguaging as the literary device of "linguistic imagery," as the excerpt displays external characters using Spanish and the internal voice uses English, thus displaying the contrast between how the protagonist views herself and the perceived identity of the surrounding characters.

Along with translanguaging being utilized as a literary device to reveal identity, many submissions simply show that translanguaging is naturally occurring and not solicited by another individual, as discussed in Canagarajah (2011). Although it is not entirely clear if all works use translanguaging "naturally," regardless it can be appreciated that the authors then used translanguaging to practice L2s, or others acquired or studied languages in attempts to develop an identity within a multilingual space. Therefore, still fulfilling the conceptual background behind the support of translanguaging and multilingualism. Excerpt 1 also shows an interactional strategy in translingual writing. Here, the author uses the variation in language to show a multimodal semiotic cue to represent her voice and create meaning to her literature. Since the author cannot rely on shared language for readers to interpret her writing, her language use creates a multisensory response to convey her voice and the meaning of the piece (Canagarajah, 2013). Excerpt 2, below, also begins to show the 
interactional translingual strategy. The author uses the semantic resource of the onomatopoeia "Tick Tock" to facilitate a co-construction of meaning to her piece despite the possibility of shared language norms (Canagarajah, 2013). Excerpt 2 and Excerpt 3 display how translanguaging varies among multilinguals or emerging multilinguals when provided the literary space to do so.

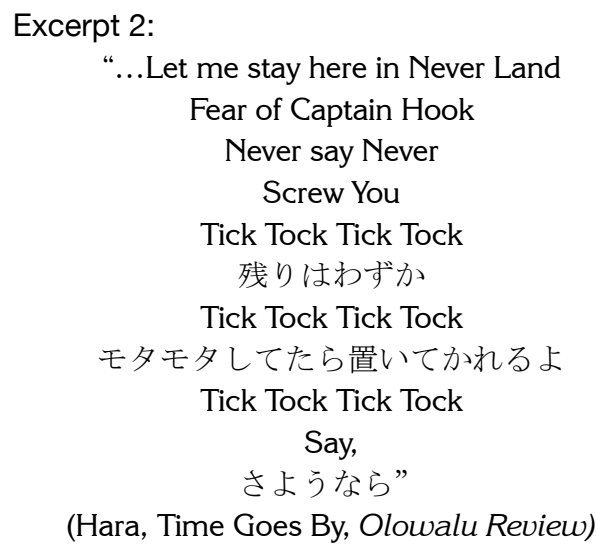

Excerpt 3:

E Lei,

e [lay laid laid] 'oe i les leis

ma luna à la lune

i laila, où elle [lie lay lain]

i le lit o lāua

(Amos, E Lei, Olowalu Review)

Where in Excerpt 2 translanguaging occurs again as a literary device though through the onomatopoeia of "Tick Tock," the author's voice is also heard through the segment only in English and the alternating phrases spoken in Japanese. In Excerpt 3, the author uses three languages, Hawaiian, English, and French interchangeably with no clear or shifting pattern. Therefore, the exact meaning of the poem would be rather difficult to comprehend for someone unfamiliar in these three languages, again showing that Olowalu Review created the space for the author's multilingual voice to foster unique expressions of identity in these three languages through translanguaging. Through the variation of translanguaging among submissions, it is quite clear that all pieces clearly display the translingual strategy of envoicing due to the nature of their creative writing literature. The unique structure of the pieces themselves, served as an interpretation into the authors' writing style, identity, and voice (Canagarajah, 2013). While some of Canagarajah's translingual writing strategies were not as distinctly visible or as important to discuss, such as recontextualization and entextualization, this may be due to the freedom of genre allowed in Olowalu Review. Whereas recontextualization is focused on structuring a text according to a genre and extextualization in the process and drafting of a text, the fact that these literary pieces were only categorized according to genre by the author requiring no structural format, and requiring an unedited one-time submission makes the current analysis less rich in its ability to support them. Although the authors did entail some structure to their writing, opening a discussion on the translingual strategy of recontextualization, pursuing a genreanalysis of submissions was not seen necessary by the researcher due to the pursuit of analyzing and viewing the pieces as open literary expression.

After several discussions with authors in regards to their feedback on Olowalu Review, two prominent perspectives prevailed and motivated numerous authors to write for the magazine: space and acceptance. Although a few authors did say that writing their pieces was a bit challenging, they viewed the opportunity to submit as a way to practice the languages they have previously studied. When asked about the experience they replied with phrases such as "it was fun," "interesting," and a "good way to practice." For many, there was an intrigued sense in why they would do this, but afterwards having a feeling of enjoyment and satisfaction. Particular authors were pleased to finally have a location to publish their work because they in fact were multilinguals and translanguaging naturally occurred in their written literature. After interviews with authors, many found the researcher's analysis to be interesting and an interesting discussion on their own writing and literary voice, showing them the uniqueness in their multilingual expression, and, consequently, showing the need for multilingual spaces not only within language learning classrooms but also on a much larger scale. One author in particular felt a great deal of acceptance through the ability to write in his native language alongside English. By writing a bilingual poem in 
Arabic and English, he felt that in this multilingual space an identity through both languages could be expressed. He felt this acceptance was well needed due to current and historical issues relating to his native language, culture, and country within the English speakers' culture and countries. Developing translanguaging spaces can help to promote the feeling of linguistic acceptance and equality which, being viewed as a clear human right, can transcend greater tolerance towards others.

\section{Pedagogical Implications}

There are several pedagogical implications that can be drawn from Olowalu Review specifically relating to the language-learning classroom and multilingualism. One of the first and most practical applications from such a project could be developing language and technology skills. An instructor of a foreign or second language could create or have students create websites in the target language. Since there are a variety of free online website design platforms to choose from, this is relatively easy as long as the students have access to a computer or Internet. Students could then design their own literary magazine, or branch away from literature and develop a forum on current issues, culture, history etc., through the use of translanguaging which provides the opportunity for students to not only learn technological skills but also the freedom of linguistic expression.

If the instructor or students decide to develop an online literary magazine open to poetry or other creative writing, the above findings do show that it enables learners to function and express themselves through translanguaging. Although learners will most likely translanguage differently, it still facilitates the expansion of the multilingual identity. It may even be viewed as an opportunity to move towards a more critical pedagogy on social issues, allow the expression of those otherwise rather sedentary in the target language, or promote tolerance and equity needed in a democratic society. Also, by providing the opportunity for students to utilize their full linguistic repertoire, they have the chance to uniquely practice their L1, L2, acquired, or target languages. In Olowalu Review, authors enjoyed writing their pieces and felt a sense of accomplishment after they submitted. Therefore, for emerging multilinguals, translanguaging through creative writing may provide them the resources to complete the task rather than become unmotivated by an activity they feel is out of their target language proficiency. Also, Canagarajah (2013) recommends that translingual strategies are not explicitly taught to students, rather that strategies occur naturally through the students' own terms through facilitating awareness raising and the development of writing practices. This article does not explicitly discuss awareness raising or development of writing practices in terms of teaching translingual strategies; more so it focuses on providing the space and the awareness of translanguaging's existence. Instead, these strategies should be taken into account in terms of understanding the context and use of translanguaging in multilingual writing. The assessment of translingual strategies could become problematic as mentioned in Canagarajah's work, due to the teacher's own translanguaging development and difficulty leaving established academic norms. Although several other pedagogical implications can be investigated out of the Olowalu Review project, the goal of this article is to display how such endeavors can help foster learner or multilingual identity and be a great outlet or space to practice target or acquired languages.

Lastly, not so much as a pedagogical implication but rather a duty of an educator is to allow such spaces for arts and expression to exist. Being in language education consequently raises the responsibility of creating and promoting multilingual and translanguaging spaces for not only students but also members of the larger community. Simple projects like Olowalu Review can help educators accomplish their duties to their students and society.

\section{Conclusion}

The development of Olowalu Review occurred as a result of an instructor seeing the inability his students had to express themselves as emerging multilinguals. With the recent shift towards new theory and modes of approaching multilingualism in the language learning classroom, there is a clear need for translanguaging space where multilinguals can have the opportunity to develop and foster identity. Olowalu Review attempted to provide not only 
students and the instructor's home institution but also members of the larger multilingual community translanguaging space through creative writing. The initial goals of Olowalu Review were met; however, there is clearly room for improvement. Future projects could dive more deeply into the process of translanguaging of the authors, or discussion of why the authors chose to write about specific topics and further examine how Canagarajah's (2013) strategies impact the writing process of the authors. Also, developing multiple issues of one magazine may also increase publicity for the magazine, gaining a wider range of submissions and readership. Regardless of research propositions, all language instructors could develop a similar project to Olowalu Review. Whether the focus is simply another opportunity to practice the L1 or L2, develop technological skills, or foster multilingual identity, such a project can have impacting implications in or outside the classroom. Olowalu Review by no means was an overly difficult project to carry out, all it comes down to is if language educators want to truly be involved in the changes occurring in our multilingual society and fostering adequate space for learners to grow.

Link to Olowalu Review: http://olowalureview. wix.com/olowalureview

\section{References}

Alim, H. S., Ibrahim, A., \& Pennycook, A. (2009). Global linguistic flows: Hip hop cultures, youth identities, and the politics of language. London, UK: Routledge.

Amos, K. (2015). E lei. Olowalu Review 1. Retrived from http://olowalureview.wix.com/olowalureview\#!e-lei/ cm6k.

Anzaldúa, G. (1987). Borderlands/La frontera. San Francisco, CA: Spinsters/Aunt Lute Book Company.

Baldacci, L. (2015). Calle San Miguel. Olowalu Review 1. Retrieved from http://olowalureview.wix.com/ olowalureview\#!calle-san-miguel/c208c.

Canagarajah, S. (2011). Translanguaging in the classroom: Emerging issues for research and pedagogy. In L. Wei (Ed.), Applied Linguistics Review, 2 (pp. 1-27). New York, US: Walter de Gruyter.
Canagarajah, S. (2013). Negotiating translanguaging literacy: An enactment. Research in the Teaching of English, 48(1), 40-67.

Canagarajah, S., \& Liyanage, I. (2012). Lessons from pre-colonial multilingualism. In M. Martin-Jones, A. Blackledge, \& A. Creese (Eds.), The Routledge handbook of multilingualism (pp. 49-65). London, UK: Routledge.

Cenoz, J. (2013). Defining multilingualism. Annual Review of Applied Linguistics, 33, 3-18.

Davis, K. (2009). Agentive youth research: Towards individual, collective and policy transformations. In T. G. Wiley, J. S. Lee, \& R. Rumberger (Eds.), The education of language minority immigrants in the USA (pp. 202-239). Clevedon, UK: Multilingual Matters.

De Mejía, A. M. (2005). Bilingual education in South America. Buffalo, NY: Multilingual Matters.

García, O., \& Wei, L. (2013). Translanguaging: Language, bilingualism and education. New York: Palgrave Macmillan.

García, O., Zakharia, Z., \& Otcu, B. (2013). Bilingual community education for American children: Beyond heritage languages in a global city. Bristol, UK: Multilingual Matters.

Hara, T. (2015). Time goes by. Olowalu Review 1. Retreived from http://olowalureview.wix.com/ olowalureview\#!time-goes-by/ca2w.

Phillipson, R. (1998). Globalizing English: Are linguistic human rights an alternative to linguistic imperialism? Language Sciences, 20(1), 101-112.

Phillipson, R. (2003). English-only Europe?: Challenging language policy. New York: Routledge.

Sayer, P. (2013). Translanguaging, TexMex, and bilingual pedagogy: Emergent bilinguals learning through the vernacular. TESOL Quarterly, 47(1), 63-88.

Swain, M. (2006). Languaging, agency and collaboration in advanced second language learning in $\mathrm{H}$. Byrnes (Ed.), Advanced language learning: The contributions of Halliday and Vygotsky (pp. 95-108). London, UK: Continuum.

Wei, L. (2010). Moment analysis and translanguaging space: Discursive construction of identities by multilingual Chinese youth in Britain. Journal of Pragmatics, 43(5), 1222-1235. 